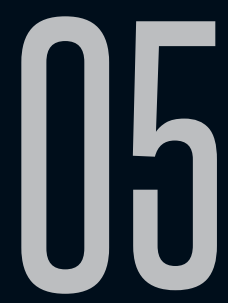

\title{
NAS BORDAS DO TEMPO: A REPRESENTAÇÃO SIMBÓLICA DO DUPLO VAMPIRO/JUDEU ERRANTE EM UM CONTO DE AGUALUSA
}

Maira Angélica Pandolfi

Tiago S. Cruz

Recebido em 04 out 2020. Maira Angélica Pandolfi é doutora, professora na Aprovado em 14 dez 2020. Universidade Estadual Paulista "Júlio de Mesquita Filho" SP, campus Assis, líder do grupo de pesquisa Narrativas Estrangeiras Moderna, pesquisadora do grupo de pesquisa Vertentes do fantástico na literatura e membro do GT ANPOLL Vertentes do Insólito ficcional. http://lattes.cnpq.br/5248539478534906 https://orcid.org/0000-0001-8547-4122 m.pandolfi@unesp.br

Tiago S. Cruz é mestrando pela Universidade Estadual Paulista "Júlio de Mesquita Filho" SP, campus Assis. http://lattes.cnpq.br/9716706257347864 https://orcid.org/0000-0001-7085-195X tsdcruz@gmail.com

Resumo: No conto "O último dia do ano", do escritor angolano José Eduardo Agualusa, dois velhos conhecidos que vagam, há séculos, por cenários catastróficos, tem um encontro marcado em um restaurante de Manhattan. São heróis desterritorializados, figuras mitológicas que carregam uma maldição histórica: a de vagar por toda eternidade. Assim, vampiro e judeu errante 
perambulam por espaços reais, carregados pela corrente fluida do tempo. Eles penetram na memória dos acontecimentos passados e, ao mesmo tempo, anseiam pela ruptura do interminável ciclo da vida, como se esperassem por um milagre. Há também um terceiro elemento, denominado "ELE" para compor a tríade da (arqui)estrutura vampírica, conectando passado e futuro nessa borda do tempo, nesse místico cronotopo que é o último dia do ano em Manhattan. A análise se pauta em uma leitura a partir da perspectiva simbólica, contando com os estudos de Bruno Berlendis de Carvalho (2010) e Pierre Brunel (2005) para a reflexão sobre a visitação aos mitos literários do vampiro e do judeu errante, além do aporte teórico de Stuart Hall (2003) sobre as diásporas e de reflexões sobre a cultura e o entre-lugar, tratados por Homi Bhabha (1998). Consideramos, ainda, as contribuições de Maurice Halbwachs (1990) sobre o tema da memória coletiva e das relações entre memória e história. A partir disso, concluímos que as figuras míticas utilizadas por Agualusa problematizam questões recorrentes em seu projeto político-literário. É o caso das diásporas, que desencadeiam relações complexas de identidades fronteiriças e de memória na PósModernidade.

Palavras-chave: José Eduardo Agualusa. Literatura Fantástica. Mito do Vampiro. Mito do Judeu Errante. Diáspora.

Abstract: In "O último dia do ano" ("the last day of the year") tale by the Angolan writer José Eduardo Agualusa, two old acquaintances who have wandered catastrophic scenarios for centuries, have a scheduled encounter in a restaurant in Manhattan. They are deterritorialized heroes, mythological figures who carry a historic curse: wandering through all eternity. Thus, being a vampire and wandering Jew wander through real spaces, carried by the flowing current of 
time. They penetrate the memory of past events and, at the same time, yearn for the rupture of the endless cycle of life, as if they were waiting for a miracle. There are also a third element, named "HE" to compose the triad of vampiric architecture, connecting past and future in that edge of time, in this mystical chronotope that is the last day of the year in Manhattan. Thus, the analysis is guided by a reading from the symbolic perspective counting on studies by Bruno Berlendis de Carvalho (2010) and Pierre Brunel (2005) for reflection on visitation of the literacies myths of the vampire and the wandering Jew, In addition to the theoretical Stuart Hall (2003) about the diasporas and reflections on culture and between places, handled by Homi Bhabha (1998). We also consider the contributions of Maurice Halbwachs (1990) on the theme of collective memory and its relations with histories. From this, we conclude that the mythical figures used by Agualusa problematize recurring issues in his political-literary project. This is the case of diasporas, which trigger complex relationships of border identities and memory in Post-Modernity.

Keywords: José Eduardo Agualusa. Fantastic Literature. Myths of the vampire. Myths of the Wandering Jew. Diasporas.

De acordo com Stuart Hall (2003, p. 27), na situação de diáspora as identidades se tornam múltiplas. É comum, segundo o mesmo autor, que elos naturais e espontâneos sejam interrompidos por experiências diaspóricas. Os dois personagens que figuram no centro do conto "O último dia do ano", de José Eduardo Agualusa (2013), são diaspóricos por natureza ou pela força da natureza, no caso do vampiro, e pelo destino social, no caso do judeu errante. Ambos são sujeitos de uma diáspora imposta e perambulam por cenários catastróficos de guerras, tragédias naturais e epidemias, 
sejam eles reais ou fictícios. A situação de trânsito forçada, vivida por esses personagens, dialoga com situações reais, vivenciadas por pessoas de diferentes nações, forçadas à diáspora. É importante ressaltar a feição que a cultura assume em situações diaspóricas, já que, como parte de um processo globalizante, ela adquire um caráter desterritorializante em seus efeitos. "Suas compressões espaço-temporais, impulsionadas pelas novas tecnologias, afrouxam os laços entre a cultura e o "lugar'” (HALL, 2003, p. 36). O conto em análise, com sua dimensão fantástica, denuncia também essa situação real, cujas feridas estão sempre expostas. O tema da guerra se faz presente nessa narrativa por meio de remissões indiretas, sobretudo, pela escolha dos espaços por onde transitam os personagens. É o caso de Cabul, capital do Afeganistão, região em guerra desde 1996, com intervenções norte-americanas que (segundo especulações políticas) levaram ao ataque das torres gêmeas em 2001. O vampiro histórico Vlad, personagem no conto de Agualusa, está em Manhattan, no epicentro dos ataques de 11 de setembro, e diz ao judeu errante que acabou de chegar de Cabul. Ao mencionar essa cidade, o judeu comenta que Vlad gosta de estar entre os mortos, onde palpita o sangue. O vampiro chega ao restaurante às 11 horas da noite. Em poucas linhas, o narrador condensa uma rede de informações que aludem claramente ao ataque de 11 de setembro às torres gêmeas (Cabul, Manhattan/ Nova York, 11 horas). A memória da guerra entre os Estados Unidos e o Afeganistão está posta, de forma implícita, por essas palavras, associadas em forma de rede, e cujo campo semântico exerce tensão no conto e, consequentemente, na cabeça do leitor (que não é um leitor qualquer), ou seja, desse interlocutor que 
é atravessado pela memória impactante das torres gêmeas em chamas, tantas vezes rememoradas pela tela da televisão. Maurice Halbwachs diz que "[...] um acontecimento grave sempre causa uma mudança nas relações do grupo com o lugar, seja porque modifique o grupo em sua extensão, por exemplo, uma morte, seja porque modifique o lugar [...]" (1990, p. 133-134). Assim, podemos citar, a título de exemplo, que World Trad Center, localizado em Manhattan (o coração financeiro de Nova York) simbolizava, antes do 11 de setembro, o poder econômico dos Estados Unidos. É por isso que após um acontecimento de grande impacto, nem o grupo, nem a memória coletiva e nem mesmo o ambiente material serão mais os mesmos. Esse ponto de encontro entre as memórias coletivas e as imagens espaciais é problematizado por Halbwachs e serve de fundamento para as referências espaço-temporais no conto, pois, quando o narrador evoca palavras ou nomes de lugares que ativam no leitor a tragédia ocorrida em 2001, mesmo sem citála em momento algum, o leitor é levado a associar a figura do vampiro com essas ocorrências do passado, presentes na memória histórica, individual e coletiva, que impregnam os espaços de Cabul a Manhattan. Não é apenas a lembrança da guerra, mas a imagem da ruína de um símbolo de poder de um Império, as torres gêmeas, que a televisão congelou no passado e que reverbera no presente, na memória dos leitores de hoje. A categoria espaço, portanto, está intimamente ligada a uma dada categoria de lembrança que se associa à imagem do vampiro histórico, o sanguinário Vlad Tepes, nome do personagem do conto. Até mesmo a imagem gemelar dessa memória catastrófica, indiretamente aludida, está representada na narrativa agualusiana por meio do "vampiro/judeu errante", 
formando um duplo. A suspensão temporal é um dos motivos que, segundo Carvalho (2010, p. 507), configura um aspecto comum ao vampiro e ao judeu errante. Tanto um como outro sintetizam as respostas individuais e coletivas do enfrentamento dramático do homem em relação ao tempo mortal de cada um com a sede de eternidade. A memória individual e a memória coletiva são determinantes no conto, uma vez que os personagens, condenados a viver eternamente, são portadores da memória do mundo. Esse fato, ao mesmo tempo em que desencadeia angustias no Judeu errante torna-se a razão de viver de Drácula. Trata-se de um embate simbólico, pois, para o ser humano as memórias podem trazer dor, incertezas e prejuízos de ordem social, histórica, política econômica e cultural, mas sem memória não é possível o progresso da vida humana no avanço das ideias, nas reformulações da história, na reinvenção cultural e no progresso das diversas áreas da vida humana. Está posto um conflito filosófico nos anseios dos personagens. $\mathrm{O}$ fato de serem catalisadores da memória do mundo nos leva a pensar nessa inquietação dos acontecimentos históricos transformados em discurso de esperança de dias melhores ou de descrença naquilo que poderia ser. A sentença de Vlad quando diz ao judeu "Ele não virá mais" atua como uma alegoria ao tempo que se renova, simbolicamente, a cada ciclo anual.

Ao apoiar-se numa concepção de sujeito que não visa à idealização de um futuro utópico, menos ainda sua concretização, o texto literário de Agualusa, híbrido em mais de um sentido, persegue o diálogo com o passado, para tomá-lo em seu potencial criativo. Ao evocar a memória e ouvir as vozes da história, o escritor quer, antes de tudo, apresentar a seu leitor o novo em transformação. 0 mito 
do duplo, portanto, não se manifesta apenas nas duas personagens do conto, mas se impõe desde o título. Para os romanos, o primeiro dia do ano era dedicado ao deus Jano, um ser de duas faces, uma voltada para o passado e outra voltada para o futuro. Se ambas as personagens, formando um duplo, estão situadas nesse intervalo, nessa borda do tempo ou nesse entre-lugar, há que se considerar também que tanto elas quanto nós, leitores, nos integramos a essa espera e somos frustrados, no final, pela negativa de Vlad: "Ele já não vem, amigo, não te atormentes mais" (AGUALUSA, 2013, p. 91). Estaria formada, assim, a tríade vampiresca desse breve relato de Agualusa? O vampirismo, para ser mais preciso, é quase sempre representado na literatura por essa triangulação: vampiro, vítima e vingador. Com a análise desse breve relato de Agualusa, pretendemos responder às inquietações sobre a composição desse espaço ambíguo de narrativas em trânsito ou, em outras palavras, como o autor se utiliza dessa (arqui)estrutura simbólica da narrativa mítica de vampiro para representar temas que comportam seu projeto político-literário.

As escolhas temáticas e o gosto pelo tema das fronteiras nas obras angolanas conversam, em parte, com a vida do autor. José Eduardo Agualusa tem as fronteiras fluidas desde o seu nascimento. Filho de um português e uma brasileira, nascido no interior de Angola, transita desde muito cedo entre três identidades que atravessam sua obra e orientam os caminhos do escritor pelo mundo, interligando Europa, América e África. As identidades em trânsito, vivenciadas por ele, são marcas recorrentes em sua obra e revelam os intensos deslocamentos de um mundo em constante globalização. 
Desde que escreveu seu primeiro livro A Conjura, de 1989 (romance que lhe valeu o Prêmio Sonangol Revelação de Literatura de Angola), Agualusa estabeleceu um pacto com a narrativa histórica, quando não totalmente de tema histórico como $A$ Conjura, que narra acontecimentos da história com uma visão livre do autor, na Angola do período de 1880 a 1991, o escritor também entrelaça ficção e personagens históricos, como vemos no conto "O último dia do ano", no seu segundo livro D. Nicolau Água-Rosada e outras histórias verdadeiras e inverossímeis (1990). Segue essa marca em outros livros como Estação das chuvas (1996) uma biografia romanceada da poetisa Lídia do Carmo Ferreira, a rainha Ana de Sousa é a personagem principal em $A$ rainha Ginga de 2014. José Eduardo Agualusa é lançado para o mundo com a publicação de Nação crioula (1997), vencedor do Grande Prêmio de Literatura RTP. Desde então, já publicou mais de 20 obras sendo traduzido em mais de 25 idiomas. Há mais de uma década tem despertado grande interesse de pesquisadores colecionando vasta fortuna crítica nas universidades brasileiras e portuguesas. Todos os anos, participa de festivais e feiras de livro nos quatro cantos do mundo, em trânsito constante como seus personagens Drácula e Judeu Errante.

$\mathrm{Na}$ tessitura da obra literária agualusiana encontra-se uma problematização dos aspectos ligados ao despatriamento, desterritorialização, desenraizamento ou a impressão mesma de que estamos constantemente em trânsito, num entre-lugar. Desse modo, a experiência subjetiva do deslocamento não se restringe mais às grandes diásporas do passado, mas a um fenômeno muito corriqueiro entre nós nos dias de hoje. A própria palavra "diáspora" 
dialoga com a identidade de uma das personagens principais do conto em análise: o judeu errante. 0 termo diáspora se derivou da história do povo judeu, que resultou no Holocausto. Outra origem para essa palavra encontra-se no Velho Testamento, com a crença no "povo escolhido, violentamente levado à escravidão no Egito; de seu sofrimento nas mãos da Babilônia; da liderança de Moisés, seguida pelo Grande Êxodo - o movimento do povo de Jah - que os livrou do cativeiro, e do retorno à Terra Prometida" (HALL, 2003, p. 28-29). As fronteiras nacionais sempre transgridem os limites políticos, pois a globalização cultural a qual estamos submetidos tem efeitos desterritorializantes. Os Estados Unidos, especialmente Manhattan, espaço do conto onde estão situados os personagens diaspóricos é, por excelência, um espaço multicultural, tanto heterogêneo como homogêneo, um espaço de encontro entre diferentes povos. $\mathrm{O}$ tema da memória é recorrente na obra agualusiana e também é enfatizado no conto, pois a busca das personagens por um lugar no mundo, o anseio pelo novo e outras inquietações, remetem sempre ao tema memorialístico. Isso ocorre em $O$ vendedor de passados (2004), livro que ganhou o Prêmio Independente de Ficção Estrangeira do jornal The Independent e que, no Brasil, foi adaptado ao cinema.

É nessa pausa breve ou interrupção temporária, que geralmente nos insufla de boas expectativas, que o escritor angolano situa seu cronotopo principal: a megalópole Manhattan e o último dia do ano, que pode ser o último dia de um ano qualquer de nosso tempo.

A tradição cultural do vampiro e suas representações literárias reflete a marca da pluralidade. O vampiro, assim como o judeu errante, são personagens centrais da narrativa em questão, 
publicada no livro Catálogo de luzes (os meus melhores contos), de 2013. A história narra o encontro entre dois amigos no último dia do ano em um restaurante em Manhattan. O primeiro a chegar é Vlad, que se senta em um canto recluso e menos iluminado do restaurante; alguns minutos depois surge o judeu Ahasverus, "abraçam e beijam-se no rosto" (AGUALUSA, 2013, p. 90), eles conversam sobre o que cada um tinha feito durante $\mathrm{O}$ ano, sobre vinho e as memórias de Vlad dos Cárpatos, bem como sua recente chegada de Cabul. Ahasverus comenta com melancolia sobre as guerras naquele país e se mostra ansioso pela chegada do ano novo. O diálogo com vampiros já havia sido amplamente trabalhado em "M. de Malária", publicado em uma coletânea de contos vampirescos organizada por Sena-Lino em 2009. O conto escolhido para essa análise encontra-se em uma sessão de narrativas que abordam temas como a individualidade do ser no tempo, desterritorialização, diálogos interculturais, identidades, deslocamentos e alguns intertextos com a cultura brasileira, marcados pela memória e pela política; características recorrentes na obra de escritores de literatura africana de língua portuguesa:

Profundamente marcada pela história, a literatura dos países africanos de língua portuguesa traz uma dimensão do passado como uma de suas matrizes de significado. A brusca ruptura no desenvolvimento cultural do continente africano, 0 contato com o mundo ocidental estabelecido sob a atmosfera de choque, a intervenção direta na organização de seus povos constituíram elementos de peso na reorganização das sociedades que fizeram a independência de cada um de seus países. (CHAVES, 2004, p. 147) 
O deslocamento geográfico, o peso da memória, questões identitárias e políticas estão entrelaçadas sob as diversas camadas ficcionais dessa narrativa breve. A narrativa de Agualusa salienta aspectos da história humana perpassados pela memória das personagens míticas, apresentando-se, assim, com um modo de narrar diferenciado. Temas como a busca pela nacionalidade no conjunto da obra são recorrentes também em escritores como Luandino Vieira e Pepetela. Já em Agualusa, questões de identidade e nacionalidade surgem na narrativa analisadas por meio do cruzamento das fronteiras. A propósito, o que se evidencia no conto é essa experiência do humano por meio do deslocamento das fronteiras de tempo e de espaço; algo semelhante ao que ocorre em outros escritores de matriz africana pós-colonialistas:

Marcados pela experiência da fronteira, tais textos
indicam uma cartografia do espaço contemporâneo
que, ao problematizar o tempo como categoria
necessária à própria compreensão do humano,
busca uma forma de memória em que o grupo e
o indivíduo se entrecruzem. (JORGE, 2007, p. 354)

O conto "O último dia do ano" apresenta duas personagens que movimentam uma rede de significados simbólicos provenientes de contextos culturais complexos e híbridos. O vampiro, por exemplo, embora seja uma criatura fantástica, confunde-se com um ser humano comum e desfila, sempre, por cenários reais. Para que um texto seja considerado fantástico este não comporta apenas o que Todorov definiu de vacilação, dúvida, diante da irrupção de algo aparentemente sobrenatural no mundo real, mas uma transgressão das leis que organizam a realidade na qual se insere o leitor. 
Como evidencia o romance de Stoker, o vampiro (e qualquer outro fenômeno sobrenatural), para o seu devido funcionamento fantástico, deve ser sempre entendido como exceção, do contrário se converteria em algo normal, cotidiano, e não seria tomado como uma ameaça (não estou falando aqui, evidentemente, da ameaça física que o vampiro representa para suas vítimas), como uma transgressão das leis que organizam a realidade. (ROAS, 2014, p. 42-43)

O encontro entre o vampiro e o judeu errante na narrativa ocorre pela intersecção entre elementos comuns e dissonantes. Segundo Carvalho (2010), há pelo menos três ramificações do vampiro: o folclórico, o literário e o histórico. O escritor angolano elege a tradição do vampiro histórico Vlad Tepes para a sua representação literária. O romeno Vlad IV Tepes, príncipe da Valáquia, foi a personagem histórica que serviu de modelo a Bram Stoker para a criação do vampiro mais famoso da literatura e do cinema: o Conde Drácula. De acordo com o Inventario de criaturas fantásticas (2006, p. 208), de Rosa Gómez Aquino, o nome Draculea significa "filho de Dracul". Trata-se de uma palavra romena que remete ao mesmo tempo a dragão e demônio. Vlad IV Tepes era filho de Vlad Dracul e inúmeras lendas foram criadas sobre ele em virtude de sua crueldade ao utilizar a técnica do empalamento contra seus inimigos. A arquitetura simbólica na qual se insere o vampiro de Agualusa retoma os elementos tradicionais desse mito: a noite, o vinho, a vitalidade, a memória dos Cárpatos (a terra natal de Vlad histórico), Baco, o caráter forasteiro, a relação com os mortos, o sangue, a dissimulação, a crueldade, a beleza, a sedução e o brilho dos olhos. Esses elementos, referidos na 
narrativa como parte do cenário, dos hábitos do vampiro e de suas características físicas e psicológicas, contrastam-se com os elementos que o narrador se utiliza para caracterizar Ahasverus, o judeu errante, quando ambos se encontram no último dia do ano em um restaurante romeno em Manhattam:

Ahasverus é alto, mais alto ainda do que o romeno. Uma esplêndida barba de profeta cai-Ihe livremente pelo peito. A comprida e revolta cabeleira, presa na nuca num rabo-de-cavalo, ilumina a penumbra. Tudo nele foge ao vulgar mas, apesar disso, não deixa lembranças por onde passa.

"Tens o dom da invisibilidade."

"Não", contesta, "limito-me a existir o menos possível." Atravessa as eras, desde há dois mil anos, sem participar delas. Tornou-se, com o correr dos séculos, um observador indiferente das tragédias humanas. Vlad, ao contrário, não perdeu com a idade a fúria de viver. Agora mesmo, enquanto aspira o perfume do vinho, sobem-lhe lágrimas aos olhos.

"Os Cárpatos", suspira. "O chão áspero do meu país."

As uvas, explica, guardam intacta a memória da terra, o sabor do sal e do ferro, o calor do Sol. O vinho, afinal, é uma espécie de sol líquido, o único que ele pode provar. (AGUALUSA, 2013, p. 90)

Os traços estereotipados do vampiro são retomados no relato, ou seja, a sede de sangue, de carne, sintetizadas na "fúria de viver" do vampiro são contrastadas com a barba grande e o visível estado de cansaço e indiferença do judeu errante diante da vida, onde este se limita apenas a existir. Ambos estão velhos, mas, ao contrário de Ahasverus, Vlad ainda sente prazer 
e interesse pela natureza humana. O vampiro de Agualusa está relacionado ao cotidiano das guerras, um amante da luta armada, da carnificina, apaixonado por sangue. Vlad traz a guerra para bem perto de nós:

- Cheguei ontem de Cabul...

- Ah, é claro! Onde há guerras, ou epidemias, ou matanças, ou a possibilidade de que isso aconteça, lá estás tu. Aprecias viver entre os mortos... (AGUALUSA 2013, p. 90)

Um Vlad muito próximo à personagem histórica, entretanto, situado em um cenário do século XXI, com um discurso repleto de nuances irônicas e jocosas que dialogam com a personagem literária de Bram Stoker, porém, ligado às mazelas do mundo contemporâneo. Encontra-se em Nova York, em um restaurante, na virada do ano; é um homem do nosso tempo. Um elemento insólito que caracteriza Vlad no início da narrativa é o uso de óculos escuros às 11 horas da noite, quando adentra o restaurante romeno, onde é imediatamente reconhecido pelo dono, seu conterrâneo. Além de esconder o brilho incomum dos olhos, outro traço recorrente no vampiro, o uso de óculos escuros imprime um ar de jovialidade ao velho Vlad em contraste com as barbas brancas e proféticas do judeu, que lhe imprimem um ar longevo. A simbologia do olhar vampiresco está presente em inúmeros textos literários, pois "o olhar é por excelência o meio de sedução e do poder de enfeitiçamento que o vampiro exerce sobre a vítima. Via de regra, não é pela força que o vampiro subjuga a vítima, mas é o seu fascínio a fazê-Io" (CARVALHO, 2010, p. 493). O olhar simboliza esse jogo ambíguo entre o esconder-se e o desvelar-se. 
O vampiro, ao contrário do judeu errante, é da ordem do sobrenatural e pode ser classificado como um monstro. A dissimulação, uma de suas características mais peculiares, oculta sua verdadeira natureza. É assim que Vlad se auto define na narrativa: "Olho para mim próprio e sabes o que vejo? Uma flor carnívora. Certas flores cultivam a beleza, vestem-se de cores brilhantes, enfeitam-se e perfumam-se para melhor atraírem as vítimas. Sou cruel? Pode ser. A natureza é cruel" (AGUALUSA, 2013, p. 91).

O encontro de Vlad com o Judeu errante é, na verdade, o encontro com uma figura trágica, condenada a vagar por toda eternidade. Por essa razão, a errância no judeu assume um caráter alegórico, pois é fruto de um castigo. No sentido alegórico, MarieFrance Rouart assinala que "cada autor pode ver nele, de fato, o porta-voz de uma ideologia ou de uma controvérsia" (2005, p. 667). Se ambos, Vlad e Ahasverus compartilham traços comuns como longevidade e maldição não podemos dizer o mesmo da errância de cada um deles e do sentido que esta assume no texto de Agualusa. Para Rouart, "o caráter errante de Ahasverus propõe aos escritores um arcabouço dramático apto a simbolizar a condição de todo homem em seu enfrentamento com o espaço e o tempo". Na narrativa do escritor angolano é sobre o Judeu que recai o valor negativo do drama da errância, ao passo que, por outro lado, o vampiro assume o polo positivo desse mesmo drama. Ahasverus em tensão com a crueldade e jovialidade de Vlad prefigura a renovação de um tempo, a esperança de uma luz, de um novo ano, condenado a nunca chegar. Ele se projeta para o futuro ao passo que Vlad é a encarnação do nefasto presente. Na forma de duplo, Agualusa tensiona ambos personagens para encarnar em Ahasverus a sede 
por livrar-se de um tempo de guerras e instabilidades, pois somente ele espera pelo ano novo:

Faltam poucos minutos para a chegada do novo ano. Os dois homens ficam em silêncio por um longo momento. Ahasverus mergulha os olhos no vinho:

"Achas que Ele virá?"

Vlad admira-se por descobrir na voz do outro um leve sinal de ansiedade. Sorri triunfante:

"Ele já não vem, amigo, não te atormentes mais." (AGUALUSA, 2013, p. 91)

Se Ahasverus anseia pela renovação que o ano novo simboliza, Vlad é a representação da aceitação de um homem que não tem mais destino, sem utopias, portanto, um homem que não deseja mais caminhar. O vampiro anseia pela sua finitude, anseia por desfazer-se de sua condição sobrenatural de monstro para assumir a face humana da morte. Em outras palavras, o monstro anseia pela humanização, mas se depara sempre com seu monstruoso destino. A dimensão alegórica desse encontro se traduz na esperança que encarna a simbologia do ano novo, pois se renovam em ambos as esperanças; em Ahasverus a de uma nova humanidade livre dos genocídios contemporâneos e em Vlad se renova a esperança de desfazer-se de sua natureza cruel e imortal de monstro errante.

De acordo com Homi Bhabha (1998, p. 27), é possível interpretar a condição de futuro, aludida no conto pela espera do ano novo, como um "estar no além" que é, ao mesmo tempo, "habitar um espaço intermédio", ou melhor, que nada mais é do que tocar o presente e reinscrevê-lo. A cultura, por assim dizer, encontra-se nesse espaço fronteiriço ou nesse "entre-lugar" que exige a ideia 
do novo a partir de uma tradição. Nessa linha de pensamento se inscrevem os personagens do conto de Agualusa e seu explícito desejo de instaurar a ruptura na tradição de suas histórias individuais e coletivas que devemos considerar, também, como memórias individuais e coletivas. Como essas memórias dos personagens se misturam às nossas memórias, formando, ao mesmo tempo, um composto homogêneo e heterogêneo? Por meio de seu texto literário e, principalmente, da categoria espacial, o autor angolano encontra estratégias para isso.

Assim, não há memória coletiva que não se
desenvolva num quadro espacial. Ora, o espaço
é uma realidade que dura: nossas impressões
se sucedem, uma à outra, nada permanece em
nosso espírito, e não seria possível compreender
que pudéssemos recuperar o passado, se ele não
se conservasse, com efeito, no meio material que
nos cerca. (HALBWACHS, 1990, p. 143)

As imagens ou memórias individuais desencadeadas pelo vinho representam, no conto, essa relação espacial supracitada quando Vlad discorre sobre sua terra natal, a Transilvânia, também terra de Baco, e por meio dessas lembranças seu discurso adquire ares lascivos, rapidamente notados pelo velho judeu errante, que não se deixa seduzir, e o interrompe para perguntar-lhe por onde, de fato, ele perambulava. Assim como a figura do vampiro, os signos são enganadores, ambíguos, e ao menor sinal de esperança que a simbologia do ano novo alude é interposta a sua antítese, bem demarcada pelo título do conto que, em outras palavras, pode ser lido como uma senha apocalíptica (último dia). Ao discorrer sobre as imagens apocalípticas, Danièle Chauvin lembra que "o 
Fim do Universo talvez tenha acontecido há milhares de anos, pois as estrelas que contemplamos à noite estão apagadas há milênios. Então o futuro não existe. Tudo é passado, o presente é um ponto efêmero" (2005, p. 62). O Ahasverus de Agualusa é a representação do ser oprimido com o qual nos identificamos, pois, diferentemente do vampiro, ele se mostra indignado com a crueldade do outro. No discurso do judeu errante de Agualusa é possível notar uma inversão de valores do personagem em sua tradição literária que, olhando no fundo do copo de vinho, se pergunta se ELE virá. Nessa imagem coletiva de um judeu, sempre associado ao anticristo, o autor parece inscrever, em contraste com o vampiro, uma nova simbologia para Ahasverus. Essa nova imagem de um judeu errante que aparenta buscar o sentido de humanismo que falta no outro advém de releituras de inquietação romântica, notadamente de releituras francesas, segundo Rouart:

Se essa legendária figura de náufrago do tempo acumula os sinais infamantes dos herdeiros de Caim, se canta os tormentos da viagem vã, como no poema de Schlegel, Die Warnung (A advertência, 1802) ou na Canção de Béranger, Le Juif Errant (1831), ela se torna a essa altura o emblema dos povos proscritos, judeus ou massas oprimidas em luta com a miséria. Cada vez mais identificado com as figuras judaicas da atualidade no Spinoza de B. Auerbach (1837), por exemplo, o herói encarna também para A. L. Constant, em 1846, o "pobre", esse "judeu errante da civilização moderna". Nesse sentido, o sucesso do romance-folhetim de Eugène Sue, Le Juif Errant (1844-1845), é bem significativo da popularidade recém-readquirida dessa grande sombra que protege a marcha da humanidade. É frequente, para os poetas alemães, como Brentano 
e Görres, o Judeu Errante simbolizar o ser salvador e mediador de um amor, a ponto de seu caminhar sem rumo reunir os temas do perdão e da aliança. (2005, p. 670)

Inscrever a revisitação agualusiana do mito do judeu errante nessa vertente romântica pode ser algo possível, mesmo em uma forma tão sintética como o conto, já que a leitura simbólica da imagem do judeu na tessitura desse texto revela um duplo heterogêneo, contrastando-se com a monstruosidade do vampiro, além de encerrar o conto debruçado sobre um símbolo cristão, o vinho, perguntando se ELE virá. Na mitologia cristã, o sangue de Cristo, representado na liturgia pelo vinho, é capaz de criar novas vidas. O vinho e o sangue são como o vampiro e o judeu errante, representam as duas faces de uma mesma moeda, ou as duas faces de Deus. As analogias com o Anticristo na imagem de Vlad são reiteradas também pelo tópos, já que Baco, Deus do vinho, das festas e das orgias, provém da mesma terra de Vlad. O judeu errante, com sua barba de profeta e sua farta cabeleira, associa-se à figura de Cristo. Assim, o vinho é de Baco e também é de Cristo, ambos bebem, simbolicamente, do mesmo sangue. Lima observa que essa figura comporta múltiplas identidades e que ora pode ser lida como o Diabo, ora como Deus e até como Jesus Cristo. Desse modo, o estudioso conclui:

Jesus pede que seus discípulos bebam seu sangue, simbolicamente através do vinho, para que tenham vida e tenham vida em abundância no paraíso celestial. O vampiro por sua vez, utiliza o sangue das suas vítimas transubstanciando-o dentro de suas próprias veias e depois faz com que seus escolhidos bebam este sangue impuro para que 
assim se transformem em vampiros e dessa forma tenham vida eterna no mundo das trevas. Além de Satanás e Jesus percebi que o vampiro de Stoker parodiava também o próprio YHWH, pois tinha o poder sobre as intempéries da natureza e sobre animais. Entrava na mente dos humanos e conseguia hipnotizá-los e manipular suas mentes, assim como YHWH fez com o faraó e o povo Egito. (LIMA, 2016, p. 306)

O vinho/sangue, tão caro a essas figuras revisitadas por Agualusa, é tratado por meio do duplo, configurando uma das transgressões mais tradicionais do texto fantástico, ou seja, a da suspensão das fronteiras entre a vida e a morte. Reconhecendo a importância da temática do sangue na literatura vampírica, Rosalba Campra problematiza esse tema ao reconhecer sua dimensão paradoxal

[...] pois, em seu caso, não se trata de imortalidade, ou de retorno do mais além, como acontece com os mais pacíficos fantasmas, mas de "não morte": um estado intermediário, irremediavelmente maligno, pois para manter-se como tal o vampiro necessita de sangue fresco. As vítimas, mais ou menos inocentes, correm o risco de se converterem também em vampiros, dando ao infeliz oximoro do "morto vivo" a possibilidade de uma multiplicação infinita. (2016, p. 51)

Essa monstruosidade impregnada na carne do vampiro não é negada por Agualusa, mas intensificada, de forma que ao lhe atribuir um duplo com o judeu errante, inscrito em uma perspectiva romântica, aumenta-se a tensão no conto. O problema tornase ainda mais complexo quando o próprio vampiro admite que anseia por sua morte; fato que evidencia o caráter maligno da 
criatura, apontado por Campra, e, paradoxalmente, seu desejo de humanização que, como também observa a pesquisadora, já havia sido iniciado por Bram Stoker quando esse escritor lança mão da possibilidade de dar-lhe uma morte irreparável mediante a luz do dia, do fogo ou de uma estaca no coração.

\section{REFERÊNCIAS}

ABDALA JUNIOR, Benjamin. Literatura Comparada \& Relações comunitárias, Hoje. São Paulo: Ateliê editorial, 2012.

AGUALUSA, José Eduardo. Catálogo de luzes (os meus melhores contos). Rio de Janeiro: Gryphus, 2013.

BHABHA, Homi. O local da cultura. Tradução de Myriam Ávila, Eliana Lourenço de Lima Reis, Gláucia Renate Gonçalves. Belo Horizonte: UFMG, 1998.

CAMPRA, Rosalba. Territórios da ficção fantástica. Rio de Janeiro: Dialogarts Publicações, 2016.

CARVALHO, Bruno Berlendis (Org.). Caninos: antologia do vampiro literário. São Paulo: Berlendis \& Vertecchia, 2010.

CHAUVIN, Danièle. Apocalipse. In: BRUNEL, Pierre (Org.). Dicionário de mitos literários, p. 52-63, 2005.

CHAVES, Rita. O Passado Presente na Literatura Africana. Via Atlântica revista do Departamento de Letras Clássicas e Vernáculas da USP, São Paulo, n. 7, 2004. GÓMEZ AQUINO, Rosa. Inventario de criaturas fantásticas: basiliscos, aluxes, mulánimas, elfos y otros seres fabulosos. Dirigido por Marcelo Caballero; edición a cargo de Mónica Piacentini. Buenos Aires: Pluma y Papel, 2006.

HALBWACHS, Maurice. A Memória Coletiva. Tradução de Laurent Léon Shaffter. São Paulo: Vértice, 1990.

HALL, Stuart. Da Diáspora: Identidades e Mediações Culturais. Liv Sovik (Org.). Tradução de Adelaine La Guardia Resende et al. Belo Horizonte: Editora UFMG; Brasília: Representação da Unesco no Brasil, 2003.

JORGE, Silvio Renato. Demandas de um mundo contemporâneo: Agualusa, paixão e a escrita da fronteira. In: CHAVES, Rita; MACÊDO, Tânia; VECCHIA, 
Rejane (Orgs.). A Kinda e a missanga: encontros com a literatura angolana. São Paulo: Cultura Acadêmica; Luanda: Nzila, p. 349-355, 2007.

LIMA, Dante Luiz de. A vida do sangue, o sangue da vida: a influência das "sagradas" escrituras sobre a literatura vampírica. Orientador: Salma Ferraz. 2016. Tese (Doutorado em Literatura) - Universidade Federal de Santa Catarina, Florianópolis, 2016.

ROAS, David. A ameaça do fantástico: aproximações teóricas. São Paulo: Editora Unesp, 2014.

ROUART, Marie-France. O mito do Judeu Errante. In: BRUNEL, Pierre (Org.). Dicionário de Mitos Literários. Rio de Janeiro: José Olympio, p. 665-671, 2005. SALGADO, Maria Teresa. José Eduardo Agualusa: Uma ponte entre Angola e o mundo. In: SEPÚLVIDA, Maria do Carmo e SALGADO, Maria Tereza (Orgs.). África \& Brasil: letras em laços. São Caetano do Sul: Yendis Editora, p. 175-197, 2006. SENA-LINO, Pedro (Org.). Contos de Vampiros. Porto: Porto Editora, 2009. 